amphicyon nebrascensis and Protemnocyon inflatus, the last two genera and species being new. The author has a well-timed protest against the establishing of phylogenetic relations between species widely scattered in time and distribution. There is one feature about this memoir which demands special attention, and that is the date. This paper appears not to have been distributed until February, 1903, but the date on the cover is September, 1902, an apparent antedating of four months. Mere printing is not publication; an author may print descriptions of new species by the score and stack them away in the attic, but he can not, in such a case, be considered as having published descriptions of these species. In the present instance if, prior to February, 1903, John Smith had published descriptions of the two new species included in this memoir, he would justly be the author of those species in spite of the date on the cover of 'Oligocene Canidæ.' And yet the bibliographer, following the title, will credit them as September, 1902. In these days of multitudinous publications it is highly important that they should be correctly dated.

THE 'Report of the Public Museum of the City of Milwaukee' for the two years ending August 31, 1900, shows steady growth of the institution, while the list of accessions testifies to the interest of the citizens. The new custodian, Mr. Henry L. Ward, expresses his desire that the museum should become a prominent educational factor in Milwaukee, and various synoptical series have been commenced with this end in view. This particular province of a local museum is very apt to be neglected and the mistaken effort made to follow along the line of great and longestablished museums. A strictly educational museum, unless it be the Children's Museum of the Brooklyn Institute, has not yet been attempted and there is a fine field open here for some one. As Mr. Ward says, it is easy to make such a collection so deep and technical and the labels so long that they are their own undoing, but we should like to see a museum started with the education of the average visitor considered at the outset.

F. A. L.

\section{BEDELL COMPOSITE TRANSMISSIONS.}

Professor Frederick Bedell has, for some years past, been employing the electric light and power transmission lines in telephony, communicating freely wherever those lines extend. He has recently effected an important extension of his system of 'composite' transmission, utilizing a common system of distribution for both light and power transmission and for direct or alternating currents, the latter of any desired frequency. Lighting, requiring a high frequency, and power, demanding low frequencies, the one employing a single, the other a polyphase, system, may be obtained from the same system of distributing wires. The non-interference of asynchronous currents here finds its most valuable illustration. The earlier use of such simultaneous asynchronous currents in multipletelegraphy and in Bedell's telephony is now carried to its limit by systems of composite transmission for light and power purposes.

The Bedell system includes various methods of simultaneous transmission of direct and alternating currents or of alternating currents of different frequencies. One method permits the transmission of such currents both in the high-tension primary mains and in the lowtension secondary circuits. This arrangement gives an advantage over usual dispositions in the fact that low frequencies in the polyphase circuit insures satisfactory performance of all synchronous machinery, with low line-inductance and improved regulation of e. m. f. and a perfect balance of loads on the different phases.

With this system the motor loads may fluctuate, even to the extent of operating the circuit-breakers on the polyphase generators and system, without affecting the lighting system. The two systems of transmission may be regulated separately and independently, and it becomes practicable to adopt a higher load for each than would be ordinarily permissible. The line drop on the lighting circuit may be compensated by compounding at the generator and the power system of distribution is not limited in its applications by the necessity of considering the working of the lighting system. 
In low-tension secondary distribution, the direct current from the converter being introduced at the neutral points of the two distributing-circuit coils, the passage or interruption of the current thus introduced has no effect upon the action of the alternating system. A considerable variety of distribution, in detail, has been found practicable with this system, and the outcome of its adoption is expected to be a very considerable saving in cost of line and in expense of both light and power production.* It lends itself equally to distributions in light and power systems and to simultaneous operation of arc and incandescent lamps, giving a gain, often large, in the cost of copper and of line, and simplifying the whole scheme of transmission of electrical energy to multiple forms of work.

\section{R. H. Thurston.}

\section{BRAIN-WEIGHTS OF BROTHERS AND SISTERS.}

Brain-weights of brothers and sisters are not often obtained. When Professor Joseph Leidy and his brother, Dr. Philip Leidy, died within a few hours of each other, their brains, examined under similar ircumstances and by the same observer (Proıusor Harrison Allen), were found to weigh exactly the same, 45.5 ounces troy weight, or 1,415 grams. The more distinguished of the two, Professor Joseph Leidy, was also fourteen years older than his brother. Marchand, in his recent work on brain-weights, cites some interesting figures from Professor Kockel, who had the opportunity to remove and weigh the brains of three brothers and of a brother and two sisters. The figures follow:

A. BRother AND TWO SISTERS, DROWNED TOGETHER. Boy, age $4 \frac{1}{2}$ years........ $88 \mathrm{~cm} .1292$ gms. Girl, age $3 \frac{1}{2}$ years ........ 83 " 950 " Girl, age 2 years........6. 67 " 960 "

B. THREE BROTHERS, SUFFOCATED BY ILLUMINATING GAS.

Boy, age $12 \frac{1}{2}$ years .........133 cm. $1400 \mathrm{gms}$. Boy, age 8 years..........121 " 1460 " Boy, age $4 \frac{3}{4}$ years.........100 “ 1400 “

* For descriptions of some of these features and of illustrative distributions see Trans. $M$. $E$. and E. E. Assoc. of Cornell University, February 2, 1903 ; Elect. World and Engineer, February 28, 1903 ; Electrical Age, March, 1903.
It may be noted in the first instance that the brain-weight of the two-year-old girl exceeds that of the older sister by 10 grams, while the brother's, who was only $5 \mathrm{~cm}$. taller than the elder sister, exceeds her brain-weight by 342 grams. In the second instance the brain of the eight-year-old boy is 60 grams heavier than that of the older brother, while the latter's brain-weight is equaled by that of the youngest brother. It should be added that all three brains were exceedingly hyperæmic, the venous channels were filled with much blood, and the brain-substance generally was moist and soft. The brains of adult brothers and sisters are more desirable for comparison.

E. A. S.

\section{HARVARD METHOD OF TEACHING PHYSIOLOGY.*}

The new method of teaching physiology proposed in the Boston Medical and Surgical Journal, December 29, 1898, and more fully explained in the Philadelphia Medical Journal, September 1, 1900, was adopted by the Harvard Medical School in 1899.

The traditional method of teaching physiology consists of a systematic course of lectures illustrated by occasional demonstrations. For thirty years or more, especially in England, this didactic teaching has been further illustrated by certain experiments performed by the students themselves. Laboratory experiments, therefore, have long been a valued part of the instruction in physiology in many universities. When the new method of teaching was introduced in the Harvard Medical School, and two hundred students worked daily in the physiological laboratories, it was said that this was only doing in a large way that which had been done in a small way for many years. The enterprise was held to be valuable because it showed that large numbers of first-year medical students could be carried simultaneously through a long series of experiments, many of which had been thought beyond their powers; it was a lesson in faith and an example of administration, but nothing more.

* From 'Physiology at Harvard,' by W. 'T. Porter, second edition, January, 1903. 